\title{
An Overview of Interdisciplinary Exploration of Writing
}

\section{Sonali Mahanta}

Ph.D Research Scholar

Jawaharlal Nehru University

New Delhi, India

suryjasha.jnu@gmail.com

\section{Abstract}

Writing is an age-old tradition and thus the availability of theoretical explanations are also numerous. Both academically and non-academically, this skill has always been dealt with several approaches for exploring its various facets. Writing is the most preferred skill for determining literacy along with reading skill. The thematic and theoretical attempts have covered numerous discourse and can be categorised as cognitive, mix-cognitive and noncognitive $^{1}$ approaches. This research paper attempts at making a theoretical evaluation and exploration of the available approaches to writing. The exploration of writing ${ }^{2}$ as a discourse of knowledge reveals its interdisciplinary nature.

Keywords:Composition Studies, Interdisciplinary Nature, Evaluation And Exploration, Cognitive, Non-Cognitive, Hybrid-Cognitive

\section{Introduction}

The theoretical developments, for explaining writing has travelled a long way. Every phase has substantially contributed to the shaping of the historical as well as the contemporary discourse of writing as a branch of enquiry. Traditional thinkers perceive writing as a linear sequence of events, whereas the latter phases situate the product as

\footnotetext{
${ }^{1}$ Mix-cognitive signifies such perspectives that recognizes cognitive as well as non-cognitive explanations to writing.

${ }^{2}$ Writing and composition has been used interchangeably in this article.
} 
well as process-oriented views ${ }^{3}$. Moreover, the contemporary enquiry for composition studies has adopted an interdisciplinary exploration. The popular research perspectives regarding composition have absorbed concepts from linguistics, psychology as well as socio-cultural studies. The involvement of the mentioned branches makes the composition studies a potential ground for qualitative as well as quantitative investigation. In furtherance of the discussion, the upcoming sections are focusing on the theoretical approaches to writing and aim at providing a comparative construct of the same. The upcoming sections analytically elaborate the thematic development of writing theories through three types of enquiries such as cognitive, mix-cognitive and non-cognitive enquiries.

\subsection{Cognitive Enquiries}

Cognitive enquiries are being dominated by psychological investigation since the 1970s. This enquiry insight into the cognitive processes involved in writing. Prominent researchers of this phase are Hayes Flower (1980), Almargot \& Fayol (2009). Flower \& Hayes $(1980,1986)$ have employed thinking aloud protocol for investigating the deep-lying mechanism for producing a written script. According to Someren et al. (1994), the thinking aloud protocol gives data about strategies and the knowledge that the subject under study uses to construct a design and collects data regarding the reasoning procedure that are abandoned at some point and so on.

\footnotetext{
${ }^{3}$ Process oriented views are the majorly guided by the cognitive approaches.
} 


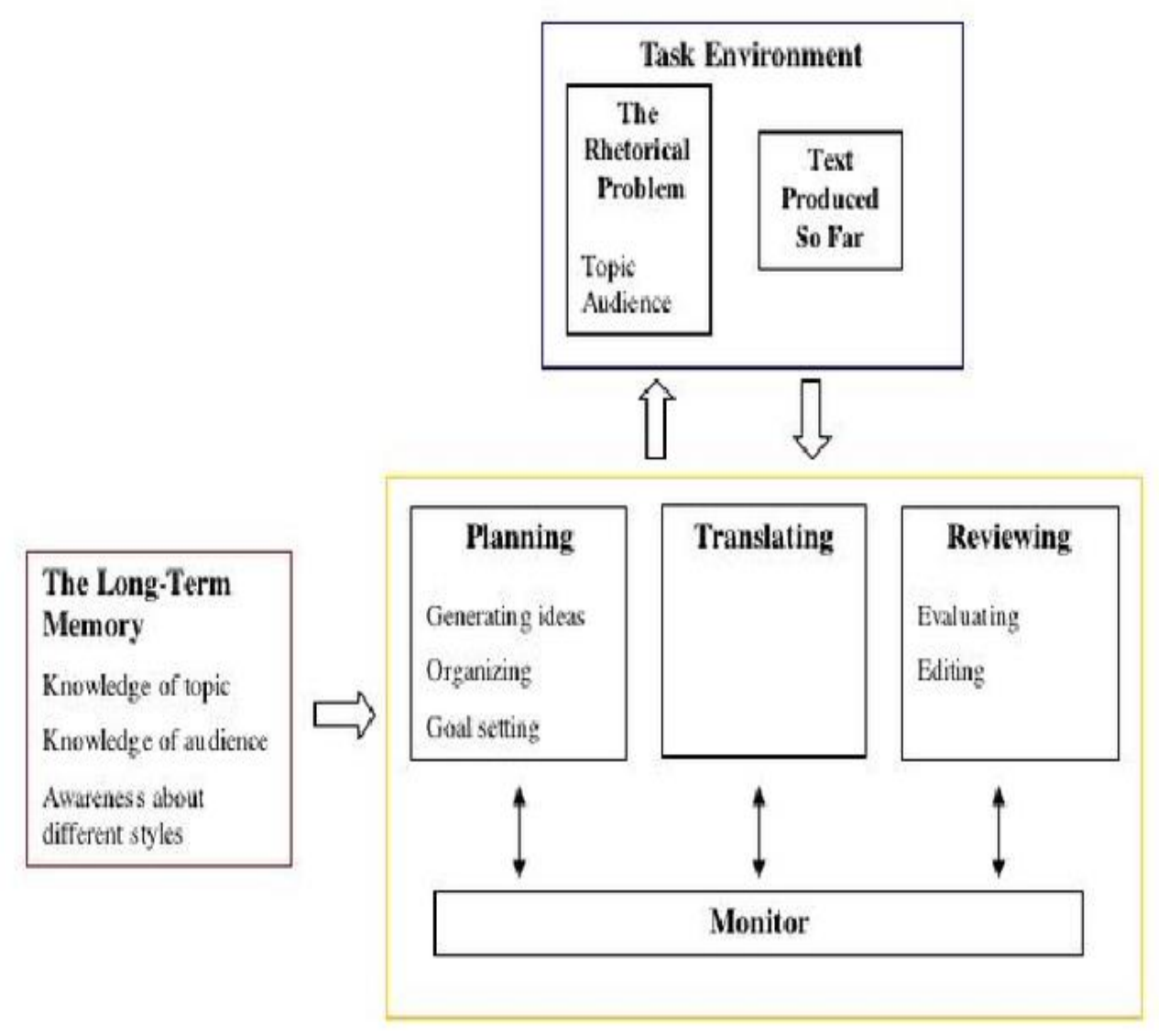

Figure 1: Flower \& Hayes model of the writing process ${ }^{4}$

Becker (1981), defines writing as a collation of a series of choices and decisions. These choices are both linguistic as well as extralinguistic in nature and build up a framework for the upcoming writing processes. The linguistic choices survive at morphological, syntactic and discourse level, whereas the extralinguistic choices signify the used processes such as conceptualisation, organisation and presentation for producing the intended composition. He further elaborates that a cognitive process involved in written composition follows a certain mechanism, which can be represented as follows.

\footnotetext{
${ }^{4}$ The above figure has been retrived fromhttps://www.researchgate.net/figure/The-Flower-and-Hayes-model-ofwriting fig1_228910541 and is used for bona-fide and fair use for academic and research purpose only.
} 


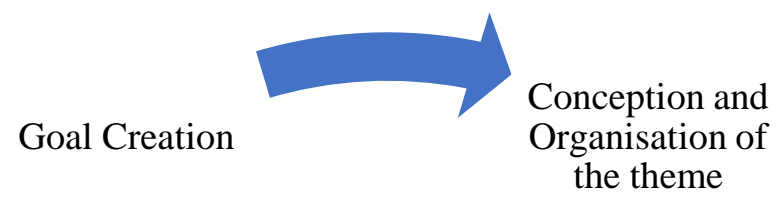

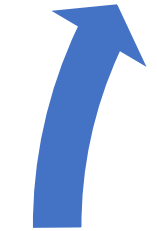

Formating the old goals

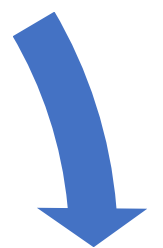

Directed and guided by a writer's own growing network

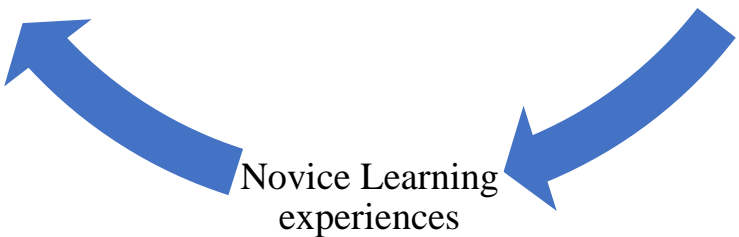

Figure 2: Mechanism involved in a written composition process

Almargot \& Fayol (2009) has surmised that a written text composition demands mobilization of conceptual and communicative knowledge in a collaborated manner along with linguistic knowledge, know-how and motor procedures ${ }^{5}$ to ensure fluent information and execution. They further stress that the lack of any of the above component results in the inefficient conduction of the task. This finally leads to the production of a substandard text.

\subsection{Mix- Cognitive Enquiries}

This approach to writing brings together elements of cognitive models of the writing process and social-cultural views including genre-based approaches to writing instruction (Chandrasegaran, 2013). He further mentions that a socio-cognitive theoretical orientation promotes the socially situated thinking processes and thus produces the generic textual features expected by their target reader. The socio-cognitive approach tries balancing the

\footnotetext{
${ }^{5}$ Motor procedures are cognitive in nature and combines motor elements for producing actions and behaviors.
} 
communication from a pragmatic ${ }^{6}$ view and that from a cognitive view and comprises of contradictory viewpoints (Khatib \&Shikaouri, 2013).

According to $\mathrm{Ng} \&$ Cheung (2018) studies exploring writing from a social perspective have stopped specifying any genre and accepted the socially recognised and practised way of language use. On the other hand, studies investigating cognitive processes or strategies for writing have highlighted numerous aspects such as generation of ideas, organisation, translating, putting thoughts, ideas from plans into sentences and reviewing. Therefore, the socio-cognitive approach derives inspiration from both for analysing a textual production

According to Lee (2011), The socio-cognitive approach helps in identifying different strategies used by different learner groups, which, in turn, helps a foreign or second language teacher to implement contextually sensitive instructions. Hence, it also adds to dealing with linguistically and culturally diverse learners more effectively. He further mentions that learners develop their strategies ${ }^{7}$ as per their unique individual histories, learning goals, and communities that they interact with. He has worked on finding the individual differences in strategy use with the help of a socio-cognitively-framed case study approach and successfully find out the learners' unique needs and goals in L2 writing demonstrated in the different setting. Cheung et al. (2021) have investigated the impact of the socio-cognitive approach on low proficiency learner and found considerable quality improvement in the written text of the same. The socio-cognitive approach integrates the pragmatic and transformative aspects of writing (Barrot, 2018). This approach depends on the psychological as well as contextual analysis of writing as a productive skill. This approach designates cooperative learning as well as peer coaching as primary and crucial to effective learning (Ammer in Barrot, 1998).

\footnotetext{
${ }^{6}$ Pragmatic view proritises context based analysis.

${ }^{7}$ Vygotsky (1978) specifies that learning strategies include an individual's higher-order mental processes, such as selective attention, intentional memory, planning, logical thought and problemsolving, learning, and evaluation of the effectiveness of these processes.
} 


\subsection{Non- Cognitive Enquiries}

Primarily, the non-cognitive enquiries ignore the cognitive perspectives related to writing. The socio-cultural and ecological approach can be included under this category.

\subsubsection{Socio-cultural approach}

This approach rejects the view that only cognitive explanations can explore the language learning process. Vygotsky in Brooks \& Donato (1994) has introduced the sociocultural approach and it investigates the socio-cultural construct of language learning. This theory has propounded that social interaction plays a fundamental role in building up strong cognition. He has also introduced two key concepts such as the zone of proximal development $(\mathrm{ZPD})^{8}$ and "scaffolding". This approach supports the contextualisation of study material and collaborative writing has been referred to as a potential technique for activating the learner's social resource for promoting learner autonomy. In sociocultural theory, learning is viewed as a social event happening as a result of interaction between the learner and the context (Lantolf, 2000).

A sociocultural approach to writing stresses every other external element that can impact writing. Its inclusiveness as an approach is more than other writing theories. It considers the individual's cultural background, experience, social activities such as collaboration, feedback. It subjects a written composition in a larger social complex network of interacting elements to identify the contributory and distributary of written composition. The analysis of the above research shows that adopting a socio-cultural approach to writing exposes a learner to gain collaborative skills, which brings in positive changes in the conceptual understanding which impacts the accuracy of their writing. This ultimately improves the writing score. This theory provides immense importance to social contexts for

\footnotetext{
${ }^{8}$ ZPD is The zone of proximal development is the gap between what a student can do independently and what they can potentially do with the help of a "more knowledgeable other

${ }^{9}$ Scaffolding is the external support supplied by a teacher to learners for
} 
learning. This theory admits that personal, interpersonal and social factors have a decisive influence on accessing the linguistic resources, interactional opportunities and L2 learning outcomes (Wood, Bruner \& Ross, 1976).

\subsubsection{Ecological Approach}

This approach explores the mutual influence of the writer and the surrounding elements. It differs from the sociological approach as the concerned approach looks for the mutual influence between the text and its environment. Both text and environment are endlessly interacting with each other. This approach has been influenced by Bakhtin in Bostard et al. (2004) ideas on the dialogical relationship between individual utterances, the work and the reader. In the context of classroom writing this relationship calls for a discussion of the relationship between individual writers, their texts, discourses in the classroom with teachers and fellow students, culture-specific norms and expectations for writing at school, values and beliefs in the societies the writers inhabit, and writers' sense of who they are or want to be in their writing (Smidt, 2021. According to this approach, writing discourse includes both inner and outer elements that possibly influence writing. The inner elements are every other participant in creating a written text such as fellow subjects and the teacher, whereas the outer element includes the culture-specific norms, social values and beliefs, where a writer co-exists and all these elements meet on an interacting platform. Patrick (2010) surmises writing as an ecological system, where every element has a specific role to play and omission of any of the elements can severely impede the goal of writing. She explains that the teaching and practice of writing survive in a complex system of theory and practice. That complex system occupies several contexts (or environments) and entities (individuals, groups, audiences). She portrays the individual as well as community nature of a written text.

\subsection{Conclusion}


The exploration of written composition in three different contexts validates several concepts concerning language learning and acquisition. The attempt to define and design writing should be a combination of cognitive as well as non-cognitive aspects, as dealing in isolation can’t provide a satisfactory explanation of writing. Cognitive investigation delves into the internal exercises for attempting a textual production. On the other hand, the noncognitive searches are dominantly enquiring for learners' personal space, where most of the interaction happens with the surrounding and for contextual support. The whole process of writing has been influenced mostly by interactive factors and dynamic situations. 


\section{References}

Alamargot, D. \& Fayol, M. (2009). Modelling the Development of Written Composition. In Writing Development: Multiple Perspectives. July 2-9. Jeffery Hall, Institute of Education, London, UK.

Baker, C. (2001). Cognitive theories of bilingualism and the curriculum. In Baker, C. (3rd ed.) Foundations of bilingual education and bilingualism,163-180. Clevedon: Multilingual Matters Ltd.

Barrot, J.S.(2018). Using the Sociocognitive-Transformative Approach in Writing Classrooms: Effects on L2 Learners' Writing Performance. Reading \& Writing Quarterly, 34(2) 187-201.

Bhowmik, Subrata. (2017). Exploring the social nature of L2 writing: Insights into the division of labor of an EAP writing task. Language and Sociocultural Theory. 4. 124155. $10.1558 /$ lst.26454.

Brooks, F. B., \& Donato, R. (1994). Vygotskyan approaches to understanding foreign language learner discourse during communicative tasks. Hispania, 77(2), 262-274. doi:10.2307/344508

study.

Bostard, etal. (2004). Bakhtinian Perspectives on Language and Culture. Meaning in Language, Art and New Media

Chandrasegaran, A. (2007). Applying a socio-cognitive model to the teaching of expository writing. Proceedings of the Redesigning pedagogy: culture, knowledge and understanding conference.

Cheung, YL., Ng, C.W., Donna,L.\& Hari, J. (2019). The "Socio-Cognitive Approach To Writing" Intervention Programme. Singapore: Nanyang Technological University 
Cheung, YL. Yin L.,Chu, Y.N.J.,\& Jang, H.(2021). Impact of a Socio-Cognitive Approach to Teaching English Language Writing on Primary School Students' Compositions. Iranian Journal of Language Teaching Research, 922

C Rish, R. M., Bylen, K., Vreeland, H., \& Wimberley, C. C. (2015). Using Google Drive to write dialogically with teachers. In M. L. Niess\& H. W. Gillow-Wiles (Eds.), Handbook of research on teacher education in the digital age (pp. 357-379). Hershey, PA: IGI Global. doi:10.4018/978- 1-4666-8403-4

Hayes, J. R., \& Flower, L. (1980). Identifying the organization of written processes. In L. W. Gregg, \& E. R. Steinberg (Eds.). Cognitive processes in writing. Hillsdale, NJ: Lawrence Erlbaum Associates. 3-30

Hayes, J. R., \& Flower, L. (1986). Writing research and the writer. American Psychologist, 41(10), 1106-1113.

Khatib, m. \&Nima, s. (2013). On situating the stance of socio-cognitive approach to language acquisition. Theory and practice in language studies. 3(9), pp.1590-1595.

Lantolf, J.P. (2000). Socio-Cultural Theory and Second Language Learning.Oxford: Oxford University Press.

Lantolf, P., \& S. L. Thorne. (2007). Sociocultural theory and second language learning in Theories in Second Language Acquisition: An Introduction in B. van Patten and J. Williams, Eds., pp. 693-701, Lawrence Erlbaum Associates. New Jersey: USA

Lee,E.J.(2011). Exploring L2 Writing Strategies from a Socio-cognitive Perspective: Mediated Actions, Goals, and Setting in L2 Writing. Doctoral Dissertation. The Ohio State University

Mohammadzadeh, A., Touran, A. \&Mahnaz, S. (2020). A Sociocultural Perspective on Second Language Writing: The Effect of Symmetrical versus Asymmetrical 
Scaffolding on Intermediate EFL Learners' Writing Accuracy, Fluency, and Complexity and Their Attitudes. Education Research International.2020.

Patrick, A.M. (2010). Sustaining Writing Theory. Composition Forum. Retrieved from: https://files.eric.ed.gov/fulltext/EJ1080578.pdf

Schmitt, B.H. (1987). The Ecological Approach to Social Perception: A Conceptual Critique. Journal for the theory of social behaviour. 17.

Smidt, J. (2021). "Developing Discourse Roles and Positionings - An Ecological Theory of Writing Development." The SAGE Handbook of Writing Development. London: SAGE Publications. pp. 117-25.

Someren, M.V., Yvonne, B. \&Jacobijn, S. (1994). The Think Aloud Method - A Practical Guide to Modelling CognitiveProcesses. Sandiego: Academic Press.

Tsui, A. B. M. (1996). Reticence and anxiety in second language learning. In K. Bailey \& D. Nunan (Eds.), Voices from the Language Classroom. (pp. 145-167). New York: Cambridge University Press.

Wood, David S., Jerome S. Bruner, and Gail Ross. (1976). “The Role of Tutoring in Problem Solving.' Journal of Child Psychology and Psychiatry 17: 89-100.

Slavkovtest, N. (2015). Sociocultural Theory, The L2 Writing Process, And Google Drive: Strange Bedfellows? TESL Canada Journal. 81, 32(2). 